\title{
Catalytic oxidation of toluene with molecular oxygen over Cr-substituted mesoporous materials
}

\author{
Ch. Subrahmanyam ${ }^{a}$, B. Louis ${ }^{b}$, F. Rainone ${ }^{b}$, \\ B. Viswanathan ${ }^{\mathrm{a}, *}$, A. Renken ${ }^{\mathrm{b}}$, T.K. Varadarajan ${ }^{\mathrm{a}}$ \\ a Department of Chemistry, Indian Institute of Technology Madras, Chennai 600036, India \\ ${ }^{\mathrm{b}}$ Institute of Chemical Engineering, Swiss Federal Institute of Technology, CH 1015 Lausanne, Switzerland
}

Received 29 August 2001; received in revised form 31 May 2002; accepted 8 August 2002

\begin{abstract}
The syntheses of thermally stable chromium-incorporating hexagonal mesoporous aluminophosphate and cubic Cr-MCM-48 have been reported. Characterization of the catalysts was made using low angle XRD, $\mathrm{N}_{2}$ adsorption, UV-VISDRS, thermal analysis, ICP-AES and ESR. Mesoporous Cr-AlPO 4 and Cr-MCM-48 catalysts have been found to be active for the vapour phase oxidation of toluene with molecular oxygen. Mesoporous $\mathrm{Cr}-\mathrm{AlPO}_{4}$ is found to exhibit both acidic and redox properties and hence oxidation as well as dealkylation reactions are taking place in a concerted manner, whereas, the cubic silicate analogue acts as a pure redox catalyst.
\end{abstract}

(C) 2002 Elsevier Science B.V. All rights reserved.

Keywords: Chromium; Aluminophosphates; Mesoporous materials; Partial oxidation

\section{Introduction}

Aluminophosphate materials, recently developed as crystalline microporous materials are of potential use in catalysis [1]. Flanigen et al. [2] reported the incorporation of various elements into the framework sites of aluminophospahtes and the resulting systems are active for various catalytic transformations. However, the pore dimensions of these materials are not sufficient to accommodate a broad spectrum of organic molecules in their cavities. With the first discovery of M41S by the Mobil researchers, a series of mesoporous materials with pore dimensions greater than $20 \AA$ have been synthesised using structure-directing templates

\footnotetext{
* Corresponding author. Tel.: +91-44-257-8250; fax: +91-44-235-0509.

E-mail address: bviswanathan@hotmail.com (B. Viswanathan).
}

[3]. The M41S series include hexagonal MCM-41, cubic MCM-48 and lamellar MCM-50. But so far, particular attention has been paid to uni-dimensional MCM-41 because of well-established synthetic strategies; hence, various transition elements have been incorporated into the framework of MCM-41 and the resulting systems are active for many catalytic reactions [4-7]. But cubic MCM-48 could be a better catalyst or catalyst support due to its interwoven and branched structure [8].

In a similar way, the strategy involved in the preparation of M41S has been extended for the preparation of mesoporous aluminophosphates. The syntheses of lamellar aluminophosphates using structure-directing templates have been reported [9]. Feng et al. reported the room temperature synthesis of mesostructured aluminophosphate via fluoride route [10]. Chakraborty et al. extended the use of cetyltrimethylammonium 
bromide for the synthesis of mesostructured silicoaluminophosphate [11]. Si, Ti and Mn have been successfully incorporated into frameworks [12-14]. Recently, some catalytic activity of Cr-substituted mesoporous aluminophosphate for the liquid phase oxidation of alkylbenzenes has been reported and it has been observed that mesoporous $\mathrm{Cr}-\mathrm{AlPO}_{4}$ shows higher activity than its silicate analogue $[15,16]$.

In the present work, the synthesis of hexagonal aluminophosphate under hydrothermal synthesis conditions is reported. The catalytic activity of this system is tested for vapour phase oxidation of toluene with molecular oxygen over $\mathrm{Cr}$-substituted $\mathrm{AlPO}_{4}$-based mesoporous material. The data obtained are compared with those obtained with Cr-MCM-48.

\section{Experimental}

\subsection{Synthesis}

Cr-AlPO 4 mesoporous material and Cr-MCM-48 have been prepared under hydrothermal conditions using chromium nitrate as chromium source. Cetyltrimethylammonium bromide (CTAB) was employed as surfactant.

1. Chromium-substituted $\mathrm{AlPO}_{4}$ mesoporous samples: Aluminum hydroxide was added to phosphoric acid under vigorous stirring. Tetramethylammonium hydroxide was added to CTAB and these two solutions were mixed under vigorous stirring. Then the $\mathrm{pH}$ was adjusted to 9.5. Chromium precursor was added finally and the stirring was continued for $12 \mathrm{~h}$ at room temperature. The resulting homogeneous gel had the composition $\mathrm{Al}_{2} \mathrm{O}_{3}: x \mathrm{P}_{2} \mathrm{O}_{5}: y \mathrm{Cr}_{2} \mathrm{O}_{3}: z \mathrm{CTAB}: \mathrm{TMAOH}$ : $w \mathrm{H}_{2} \mathrm{O}$, where $x=2.0-2.5, y=0.01-0.2, z=$ $0.4-0.5$ and $w=300-350$. The gel was then autoclaved at $423 \mathrm{~K}$ for $24 \mathrm{~h}$ and filtered and calcined at $773 \mathrm{~K}$ for $6 \mathrm{~h}$ to remove the surfactant.

2. Chromium-substituted MCM-48 samples: Sodium hydroxide was added to an aqueous solution of $\mathrm{CTAB}$ and the mixture was stirred for $30 \mathrm{~min}$. To this tetraethylorthosilicate, an aqueous solution of chromium precursor was added. The resulting

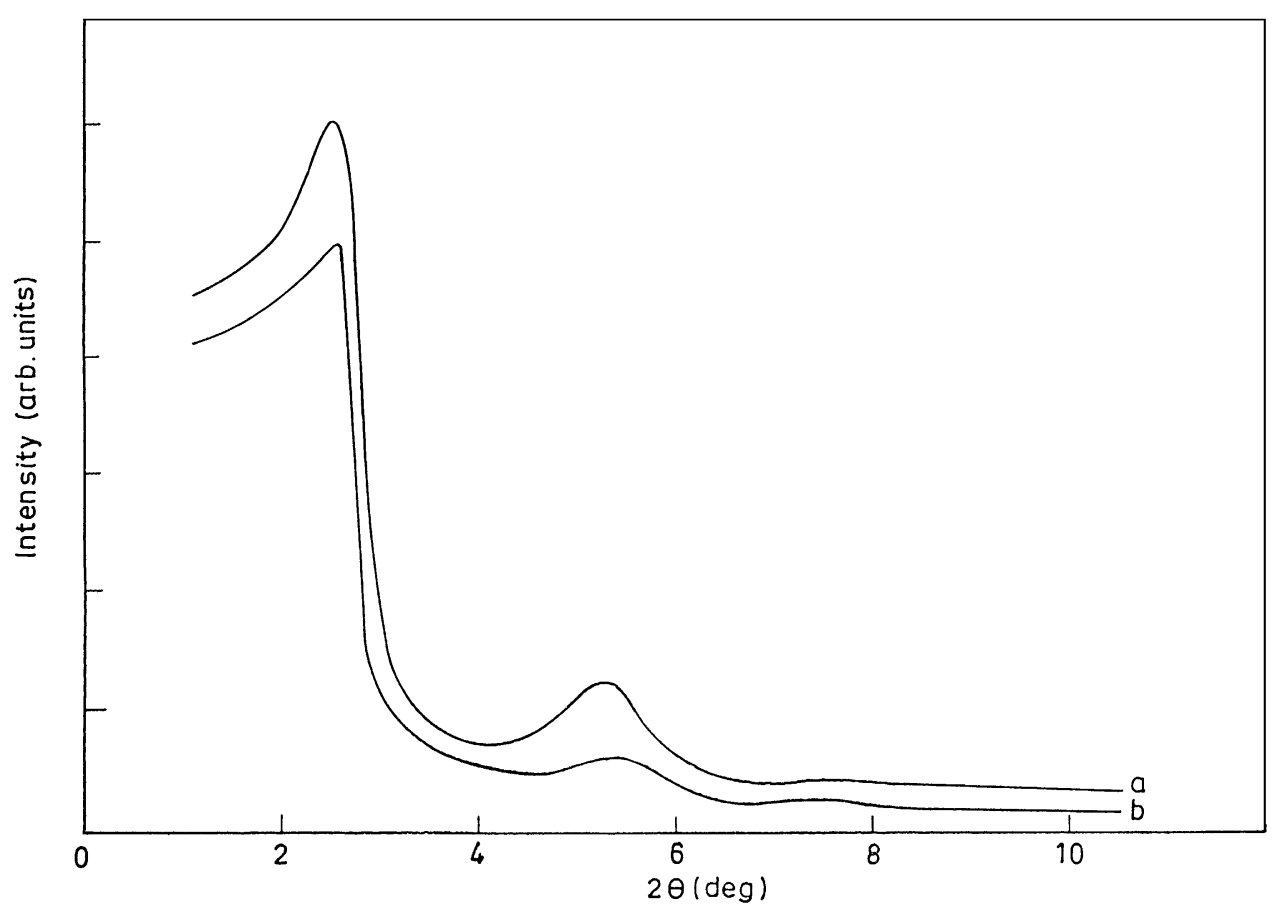

Fig. 1. XRD patterns of mesoporous $\mathrm{Cr}-\mathrm{AlPO}_{4}$ : (a) uncalculated; (b) calculated. 
homogeneous gel was found to have the composition $\mathrm{SiO}_{2}: \mathrm{Cr}_{2} \mathrm{O}_{3}: \mathrm{CTAB}: \mathrm{Na}_{2} \mathrm{O}: \mathrm{EtOH}: \mathrm{H}_{2} \mathrm{O}=$ 2.0:0.015:0.24:0.5:5.0:195. The gel was stirred for $3 \mathrm{~h}$ at room temperature and autoclaved at $423 \mathrm{~K}$ for $10 \mathrm{~h}$. Filtration followed by calcination at $823 \mathrm{~K}$ for $6 \mathrm{~h}$ resulted in the formation of Cr-MCM-48 [17]. For comparison of the surface area, the same procedure has been employed to prepare Si-MCM-48.

\subsection{Catalytic activity}

The experimental set-up consisted of three parts: the gas supply system, the reactor and the analysis system. The gases $\mathrm{O}_{2}$ (99.995\%), and $\mathrm{Ar}(99.998 \%)$ (Carba-Gas, Lausanne, Switzerland) were used without further purification. The feed was regulated through mass flow controllers. Gas mixtures A and $\mathrm{B}$ were mixed at a pressure of $101 \mathrm{kPa}$. Flow A contained oxygen, argon and toluene vapour. Flow B was used for the pretreatment of the catalyst with hydrogen and oxygen or with pure argon. The loading of the catalyst and the gas flow were maintained constant throughout the study at $0.2 \mathrm{~g}$ and $1 \mathrm{ml} / \mathrm{s}$. The catalyst was diluted with quartz powder in a 1:1 ratio. All lines and valves were heated up to $423 \mathrm{~K}$ in order to avoid any condensation of the products. The catalyst was pretreated in $\mathrm{O}_{2}\left(40 \mathrm{vol} . \% \mathrm{O}_{2}\right.$, rest $\left.\mathrm{Ar}\right)$ at $573 \mathrm{~K}$ before the reaction. The temperature was decreased and the flow was switched to the mixture of 2 vol.\% toluene plus 40 vol. $\% \mathrm{O}_{2}$ in $\mathrm{Ar}$.

\subsection{Characterization of the catalyst and reaction products}

The low-angle X-ray diffraction pattern of the sample was recorded on a Siemens D500 $(\theta / 2 \theta)$ using monochoromatised $\mathrm{Cu} \mathrm{K} \alpha$ radiation $(\lambda=1.5406 \AA)$ with a scan speed of $1 \%$ min over the range $2^{\circ}<2 \theta<$

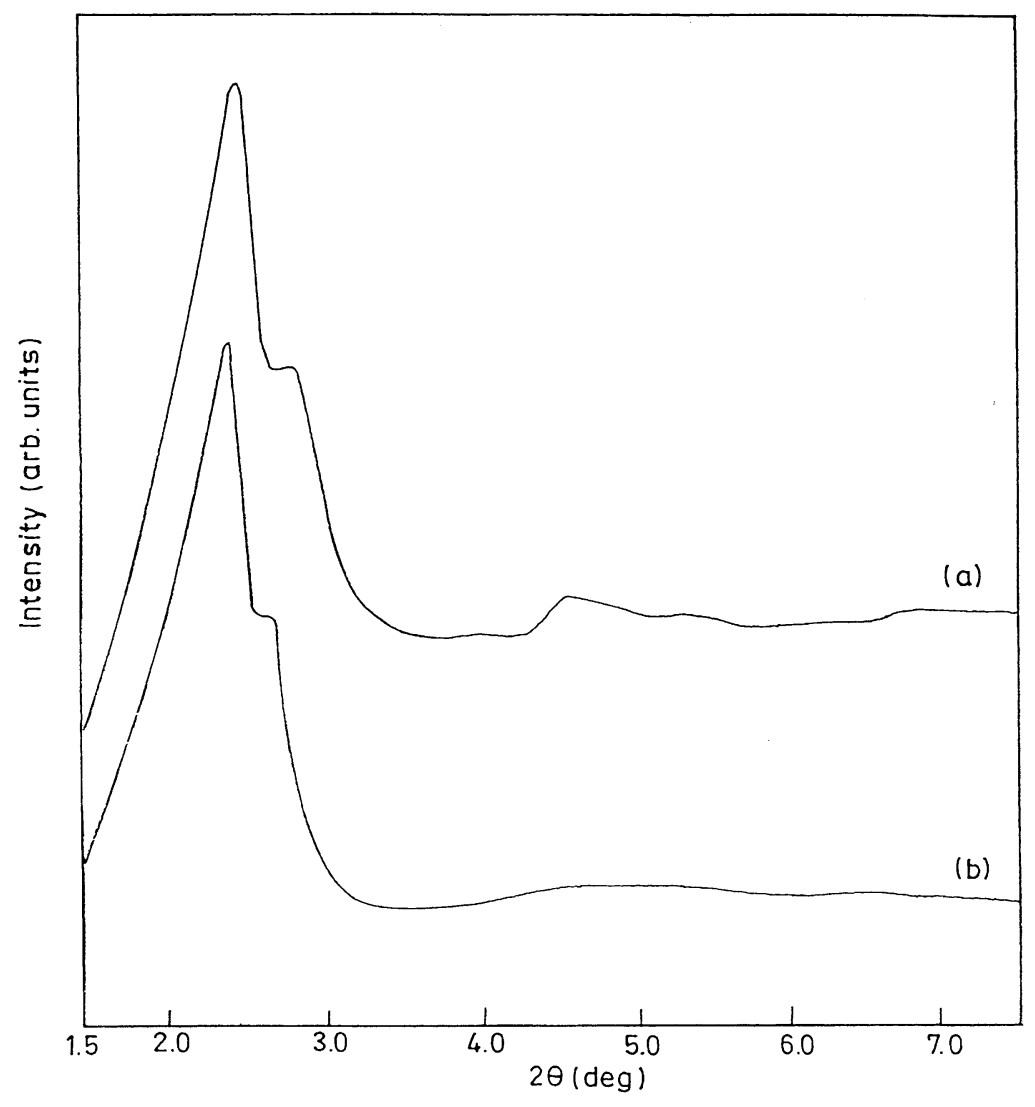

Fig. 2. XRD patterns of Cr-MCM-48: (a) uncalculated; (b) calculated. 
$10^{\circ}$. High resolution transmission electron microscopic images were observed with a Philips EM430ST operated at $300 \mathrm{kV}$. Thermal analyses of the samples were made with a thermal analyser (Perkin-Elmer model TGA 7) at a heating rate of $20^{\circ} \mathrm{C} / \mathrm{min}$. Diffusive reflectance UV-Vis spectroscopy was carried out on a Cary 5E UV-Vis-NIR spectrophotometer. ESR spectra were recorded with a Varian E-112 spectrometer at room temperature. $\mathrm{N}_{2}$ adsorption-desorption measurements at $77 \mathrm{~K}$ were made using a CE instruments, Sorptomatic 1990. The sample was out-gassed at $473 \mathrm{~K}$ for $12 \mathrm{~h}$. Temperature-programmed-reduction (TPR) studies were done using $100 \mathrm{mg}$ of the catalyst loaded in a quartz reactor. The samples were first treated with argon for $1 \mathrm{~h}$ at room temperature, followed by $\mathrm{H}_{2} / \mathrm{Ar}$. Desorption was carried out at a heating rate of $10^{\circ} \mathrm{C} / \mathrm{min}$. Temperature-programmed desorption of ammonia has been carried out in order to find out the presence of acid sites in mesoporous Cr-AlPO ${ }_{4}$ A Blazers QMG-421 mass-spectrometer and a Perkin-Elmer Autosystem XL gas chromatograph were used for the gas-phase analysis. ICP-AES has been used to obtain elemental composition. Toluene and other organic products were separated in an SPB-5 capillary column and analysed by FID. $\mathrm{Ar} / \mathrm{O}_{2}, \mathrm{CO}, \mathrm{CO}_{2}$ and $\mathrm{H}_{2} \mathrm{O}$ were analysed in a Carboxen-1010 capillary column and analysed by TCD.

\section{Results and discussion}

\section{1. $X R D$}

XRD patterns of the mesoporous aluminophosphates are shown in Fig. 1. As-synthesized materials show a $d_{100}$-spacing of $3.50 \mathrm{~nm}$. Upon calcinations, this spacing decreased to $3.34 \mathrm{~nm}$, indicating less long-range crystallographic order. The as-synthesised mesoporous $\mathrm{Cr}-\mathrm{AlPO}_{4}$ material also shows weaker but clear peaks corresponding to 110 and 200 reflections that can be indexed on the basis of a hexagonal lattice. The $\mathrm{pH}$ value of the synthesis gel was adjusted to 9.5 with tetramethylammonium hydroxide. When $\mathrm{NaOH}$ or $\mathrm{NH}_{4} \mathrm{OH}$ was used as base instead of tetramethylammonium hydroxide, only amorphous material was obtained. The function of organic ammonium cation from TMAOH is probably to modify the strength of the electrostatic interactions between the aluminophosphate species and the cationic surfactant micelle assembly to form the $\mathrm{S}^{+} \mathrm{I}^{-} / \mathrm{TMA}^{+}$ion pair. If either $\mathrm{NaOH}$ or $\mathrm{NH}_{4} \mathrm{OH}$ is used, the smaller cations $\mathrm{Na}^{+}, \mathrm{NH}_{4}{ }^{+}$compete with the aluminophosphate species and thus restrict the interaction with the positively charged cationic surfactant. It was observed that aluminium hydroxide is a better aluminium source, since it might provide a less polymerised aluminophosphate network that is favourable for the assembly of the mesostructure [18,19].

XRD patterns of the Cr-MCM-48 materials are shown in Fig. 2. Highly ordered MCM-48 mesoporous materials consistent with $I a 3 d$ cubic symmetry were obtained. In this approach, MCM-48 materials have been synthesised at lower concentrations of the template. Cr-MCM-48 shows a maximum intense peak corresponding to (211) with a $d$-spacing value of $3.59 \mathrm{~nm}$. This spacing upon calcination decreased to $3.36 \mathrm{~nm}$, indicating the contraction of the structure during calcination. However, the peak intensity remains the same, indicating that the material maintains the same morphology after calcination. Fig. 3 represents the transmission electron microscopic image of the Si-MCM-48. It can be seen that ordered mesoporous material has been synthesised under the reaction conditions.

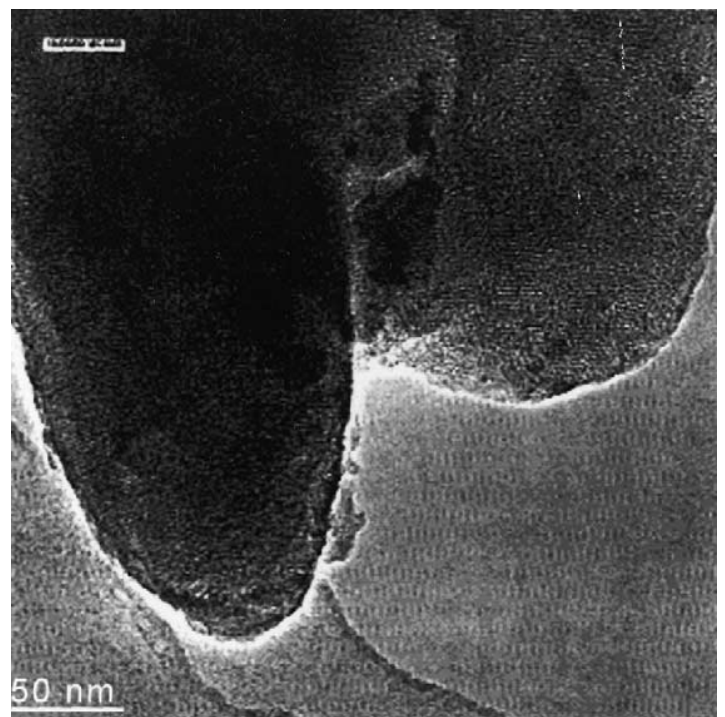

Fig. 3. Transmission electron microscopic image of MCM-48. 


\subsection{Chemical analysis and $N_{2}$ adsorption studies}

Substitution of chromium in mesoporous aluminosilicate and aluminophosphate network has been verified by ICP analysis, which resulted in 0.87 mass\% in mesoporous $\mathrm{Cr}-\mathrm{AlPO}_{4}$ and 0.93 mass\% in Cr-MCM48 respectively. Chemical composition of the materials is $\mathrm{Al}: \mathrm{P}: \mathrm{Cr}=0.92: 0.98: 0.087$ for mesoporous
Cr-AlPO 4 and $\mathrm{Si}: \mathrm{Cr}=$ 0.91:0.093 for Cr-MCM-48. Nitrogen adsorption-desorption isotherms of the Cr-AlPO 4 and Cr-MCM-48 are shown in Fig. 4. Mesoporous $\mathrm{Cr}-\mathrm{AlPO}_{4}$ mesoporous material shows a type IV isotherm with a small hysteresis loop characteristic of mesoporous materials. For all samples $\left(\mathrm{Cr}-\mathrm{AlPO}_{4}\right.$ and $\mathrm{Cr}-\mathrm{MCM}-48$ ), the isotherms are similar, having an inflection around $p / p_{0}=0.2-0.4$ characteristic of
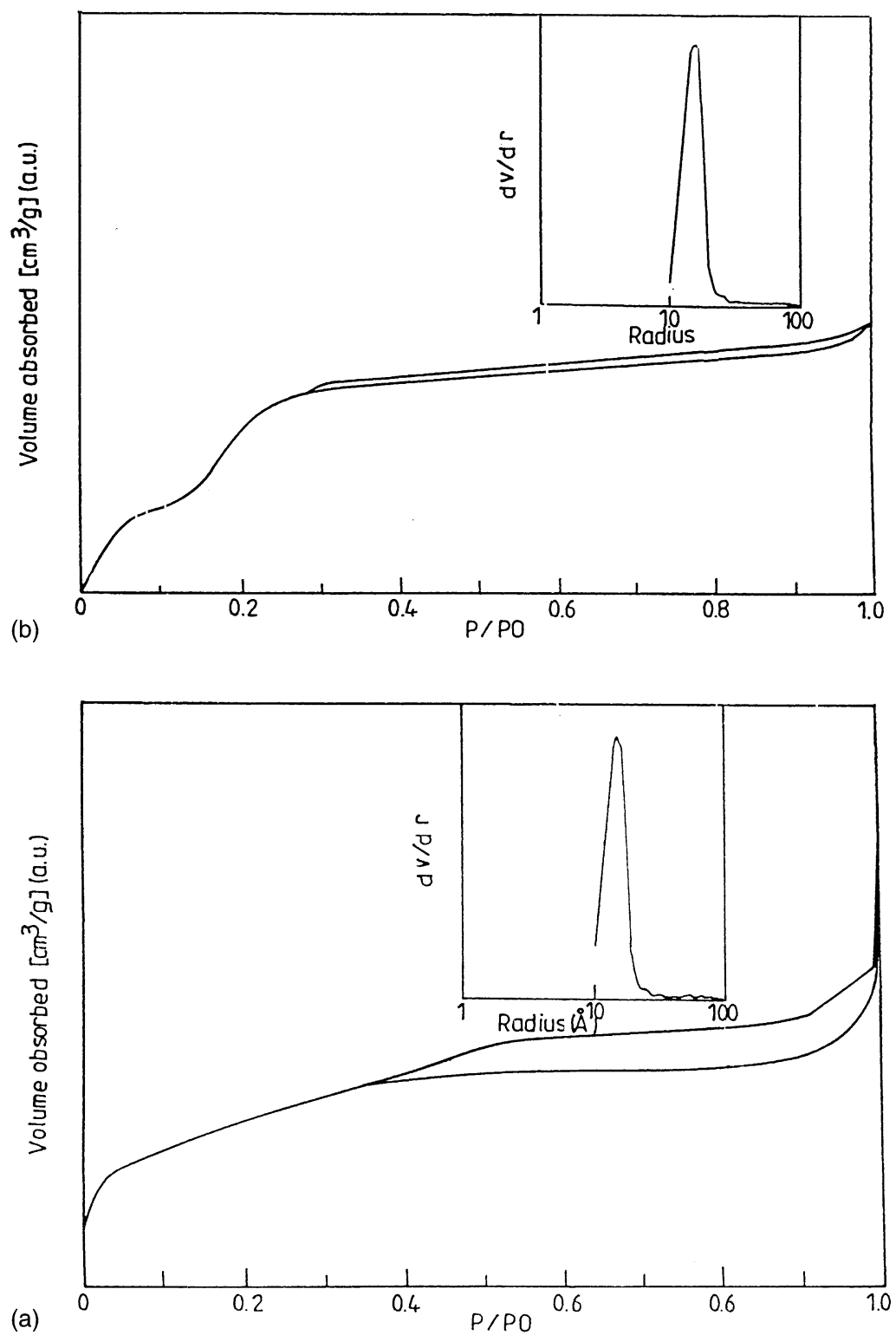

Fig. 4. $\mathrm{N}_{2}$ adsorption-desorption isotherms of (a) mesoporous Cr-AlPO 4 ; (b) Cr-MCM-48. 
Table 1

Physico-chemical properties of studied catalysts

\begin{tabular}{|c|c|c|c|c|c|c|}
\hline Catalyst & $d$ (uncalculated, $\AA$ ) & $d$ (calculated, $\AA$ ) & $a(\AA)$ & $\begin{array}{l}\text { BET surface } \\
\text { area }\left(\mathrm{m}^{2} / \mathrm{g}\right)\end{array}$ & Pore size $(\AA)$ & $\begin{array}{l}\text { Pore volume } \\
\left(\mathrm{cm}^{3} / \mathrm{g}\right)\end{array}$ \\
\hline $\mathrm{AlPO}_{4}$ & $34.5^{\mathrm{a}}$ & $33.0^{\mathrm{a}}$ & $38.10^{\mathrm{c}}$ & 685 & 28 & 0.65 \\
\hline $\mathrm{Cr}-\mathrm{AlPO}_{4}$ & $35.0^{\mathrm{a}}$ & $33.4^{\mathrm{a}}$ & $38.56^{\mathrm{c}}$ & 490 & 29 & 0.51 \\
\hline MCM-48 & $33.7^{b}$ & $32.9^{b}$ & $80.5^{\mathrm{d}}$ & 1020 & 29 & 0.99 \\
\hline Cr-MCM-48 & $35.9^{\mathrm{b}}$ & $33.6^{\mathrm{b}}$ & $82.4^{\mathrm{d}}$ & 640 & 29 & 0.70 \\
\hline
\end{tabular}

${ }^{\mathrm{a}} d_{100}$.

${ }^{\mathrm{b}} d_{211}$.

c $a=2 d_{100} / \sqrt{ } 3$

d $a=d_{211} \sqrt{ }\left(h^{2}+k^{2}+l^{2}\right)$.

mesoporous materials. The BET surface area of the Cr- $\mathrm{AlPO}_{4}$ mesoporous material is $\sim 500 \mathrm{~m}^{2} / \mathrm{g}$ and that of Cr-MCM-48 is $\sim 640 \mathrm{~m}^{2} / \mathrm{g}$. In both the cases, the pore size distributions calculated on the basis of $\mathrm{BJH}$ analysis from the desorption branch of the isotherms show a narrow distribution with a maximum around $29 \AA$. Data on physico-chemical properties of the catalysts studied are given in Table 1 .

\subsection{Thermal analysis}

Thermograms of $\mathrm{Cr}-\mathrm{AlPO}_{4}$ mesoporous material and MCM-48 are shown in Fig. 5. The thermogram of as-synthesised mesoporous $\mathrm{AlPO}_{4}$ shows (Fig. 5a) mainly two weight loss regions, one corresponding to loss of physi-sorbed water $<373 \mathrm{~K}$ and the second and the main weight loss in the temperature range
$450-550 \mathrm{~K}$ corresponding to loss of organic template. The mesoporous $\mathrm{Cr}-\mathrm{AlPO}_{4}$ is stable up to $1073 \mathrm{~K}$.

The thermogram of the Cr-MCM-48 is given in Fig. 5b, which also shows two main weight loss regions: the first one corresponds to loss of physi-sorbed water below $373 \mathrm{~K}$ and the second and main weight loss in the temperature range $473-523 \mathrm{~K}$ corresponds to removal of the template. These catalysts are stable up to $1073 \mathrm{~K}$.

\subsection{Temperature-programmed desorption of ammonia}

Fig. 6 represents temperature-programmed desorption of ammonia in the temperature range $323-823 \mathrm{~K}$. A broad desorption pattern indicates a large distribution of different types of acid sites. Deconvolution

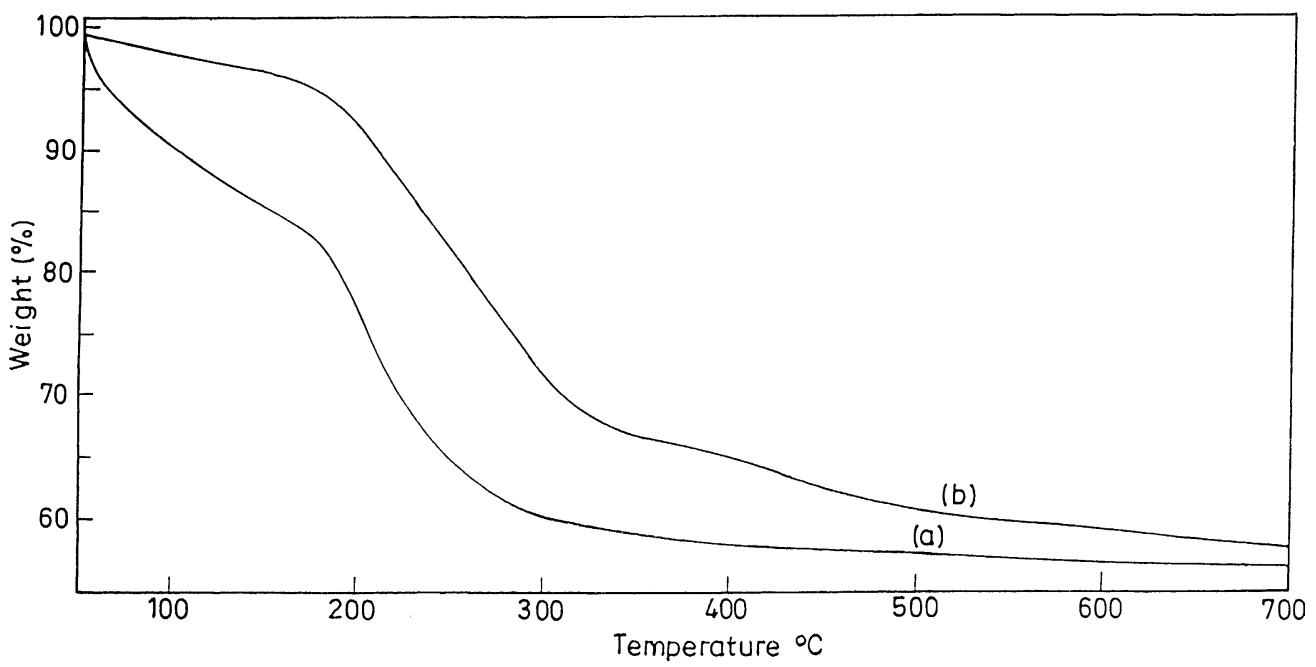

Fig. 5. TGA of (a) mesoporous Cr-AlPO 


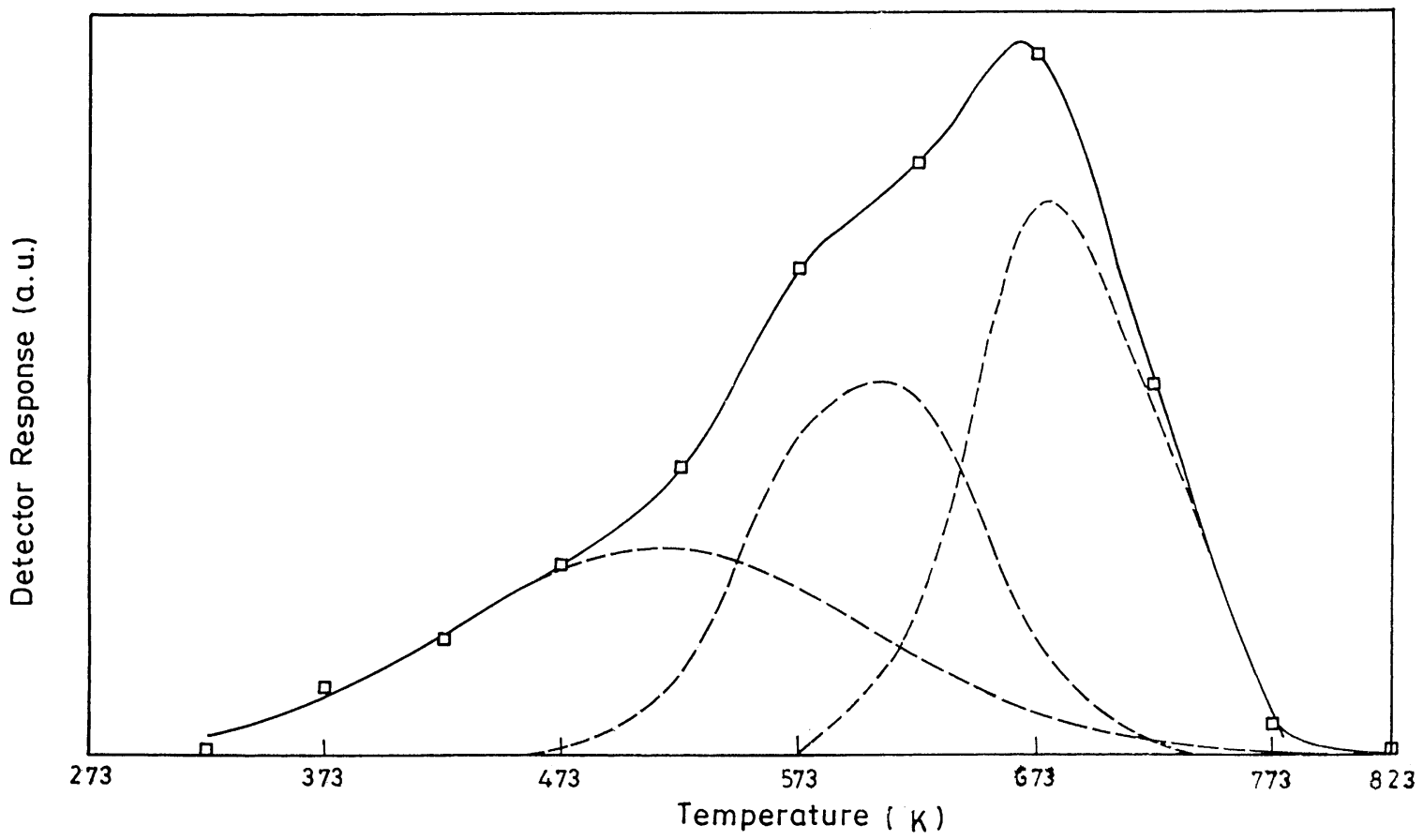

Fig. 6. TPDA profiles of mesoporous $\mathrm{Cr}-\mathrm{AlPO}_{4}$.

of the profile results in three distinct peaks in the range 323-623, 473-723 and 573-823 K. The three desorption peaks can be assigned to weakly acidic, moderately acidic and strongly acidic groups, respectively.

\section{5. $U V$-VISDRS}

Fig. 7 shows UV-VISDRS spectra of as-synthesised and calcined mesoporous $\mathrm{Cr}-\mathrm{AlPO}_{4}$ and $\mathrm{Cr}-\mathrm{MCM}-48$ samples. As-synthesised mesoporous $\mathrm{Cr}-\mathrm{AlPO}_{4}$ shows

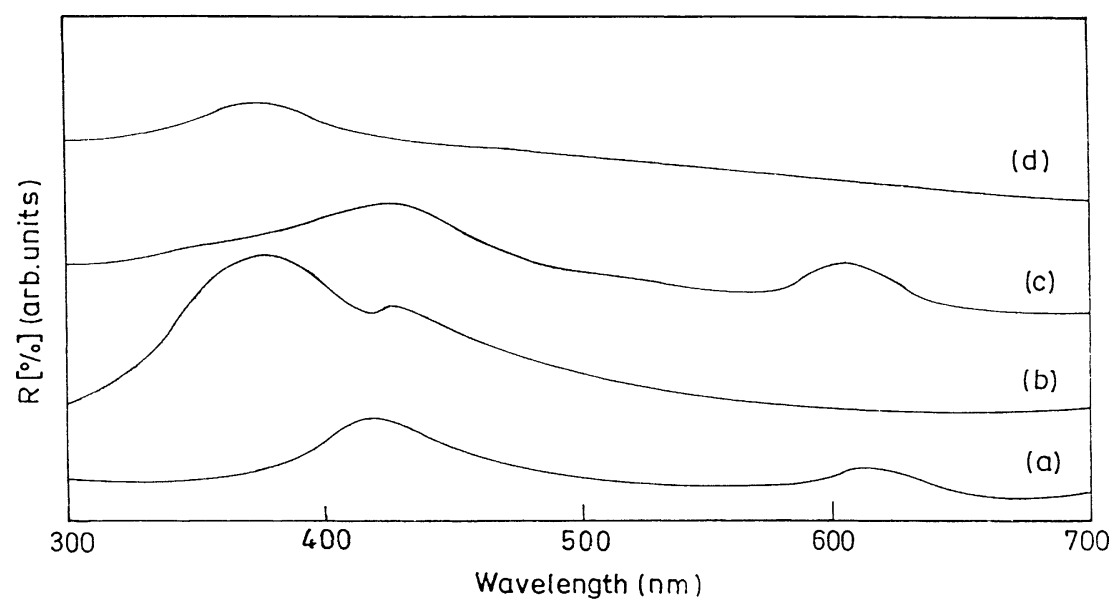

Fig. 7. Diffuse reflectance UV-Vis spectra of (a) mesoporous Cr-AlPO 4 uncalculated; (b) mesoporous Cr-AlPO 4 calculated; (c) Cr-MCM-48 uncalculated; (d) Cr-MCM-48 calculated. 
bands around 610 and $440 \mathrm{~nm}$. These bands are characteristic of trivalent chromium in octahedral co-ordination and occupying extra framework sites rather than being substituted at tetrahedral framework sites. This could be due to a large difference in LFSE between these two geometries [20]. On calcination, a new charge transfer band centred at $370 \mathrm{~nm}$ is observed, along with a shoulder at $440 \mathrm{~nm}$. This CT band could be due to $\mathrm{O}(2 \mathrm{p}) \rightarrow \mathrm{Cr}^{6+}\left(3 \mathrm{~d}^{0}\right)$ and/or $\mathrm{Cr}^{5+}$ $\left(3 \mathrm{~d}^{1}\right)$ charge transfer transitions viz., chromate-or dichromate-like species in tetrahedral environment [21].

As-synthesised Cr-MCM-48 also shows Cr(III) characteristic bands around 610 and $440 \mathrm{~nm}$, which upon calcination has resulted in an additional charge transfer band around $370 \mathrm{~nm}$, indicating the presence of chromate-or dichromate-like species in tetrahedral environment. The existence of chromium in both +5

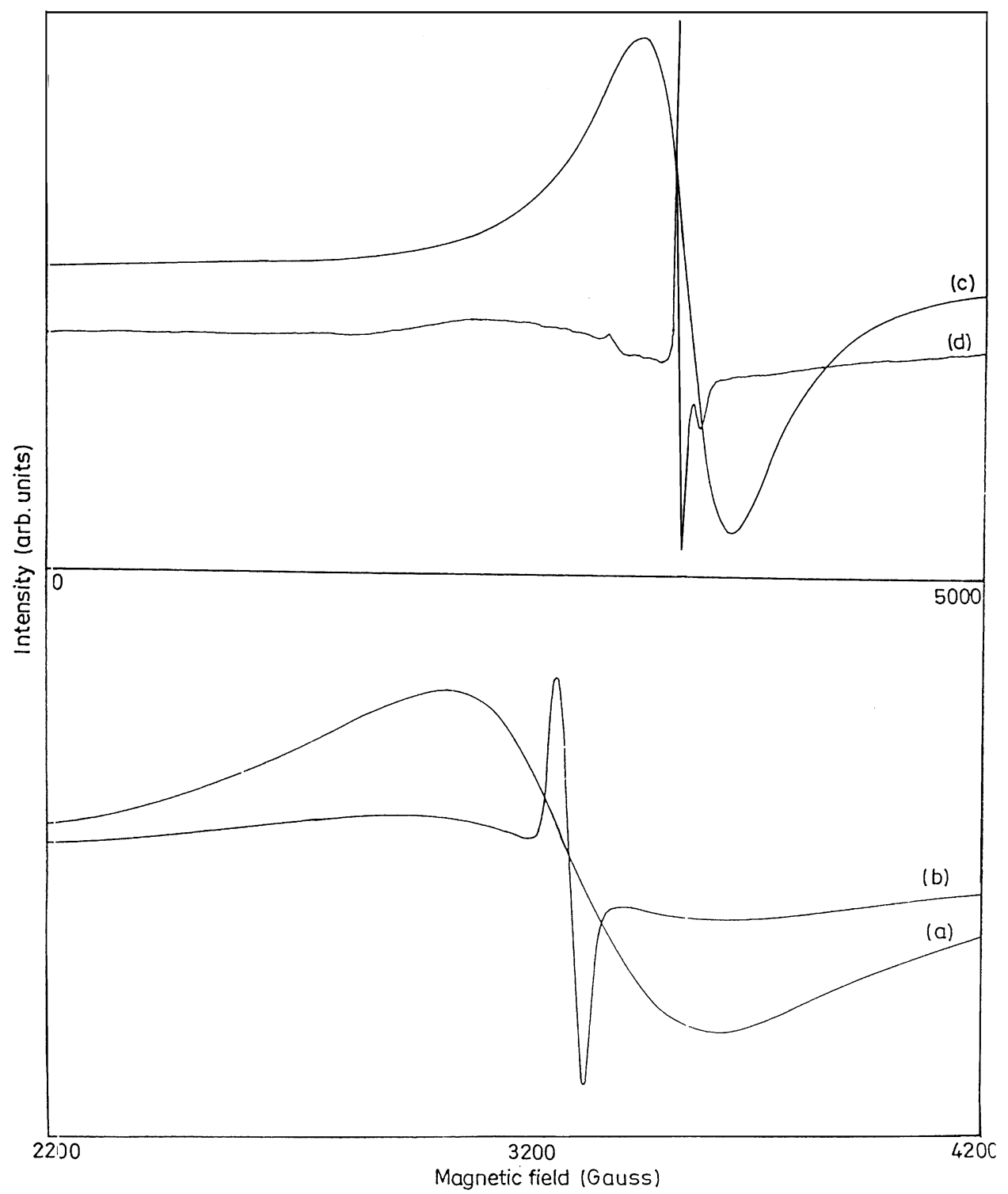

Fig. 8. ESR of (a) mesoporous $\mathrm{Cr}-\mathrm{AlPO}_{4}$ uncalculated; (b) $\mathrm{Cr}-\mathrm{AlPO}_{4}$ calculated; (c) $\mathrm{Cr}-\mathrm{MCM}-48$ uncalulated; (d) Cr-MCM-48 calculated. 
and +6 oxidation states has been further confirmed by ESR spectroscopy.

\subsection{ESR spectroscopy}

ESR spectra of as-synthesised and calcined mesoporous $\mathrm{Cr}-\mathrm{AlPO}_{4}$ are shown in Fig. 8. As-synthesised material shows a broad singlet with $g$ value of 1.98 , indicating $\mathrm{Cr}^{3+}$ ions in octahedral co-ordination [22]. The ESR spectrum of calcined mesoporous Cr-AlPO 4 shows a $g$ value at 1.97 , characteristic of pentavalent chromium in tetrahedral or distorted tetrahedral co-ordination. In a similar way, in Cr-MCM-48 as-synthesised material the presence of a broad signal around $g \sim 1.98$ suggests the presence of trivalent chromium in octahedral coordination. On calcination, the signal intensity partially decreased, resulting in a narrow signal centred at $g \sim 1.97$ which is characteristic of pentavalent chromium in tetrahedral co-ordination [22].

\subsection{Gas-phase selective oxidation of toluene on Cr-containing mesoporous catalysts}

TPR patterns of the studied catalysts in the temperature range $323-973 \mathrm{~K}$ are shown in Fig. 9. The TPR pattern of mesoporous $\mathrm{Cr}-\mathrm{AlPO}_{4}$ shows the presence of a single peak at about $713 \mathrm{~K}$, whereas, a broad reduction peak, which is centred at $730 \mathrm{~K}$ is observed for Cr-MCM-48. Activation energies for the toluene oxidation are 54 and $49 \mathrm{~kJ} / \mathrm{mol}$ on mesoporous $\mathrm{Cr}-\mathrm{AlPO}_{4}$ and $\mathrm{Cr}-\mathrm{MCM}-48$, respectively. Typical results on toluene oxidation in the temperature range $523-648 \mathrm{~K}$ over mesoporous $\mathrm{Cr}-\mathrm{AlPO}_{4}$ and Cr-MCM-48 are given in Tables 2 and 3. Benzaldehyde, benzene, $\mathrm{CO}_{2}$ and $\mathrm{CO}$ are the reaction

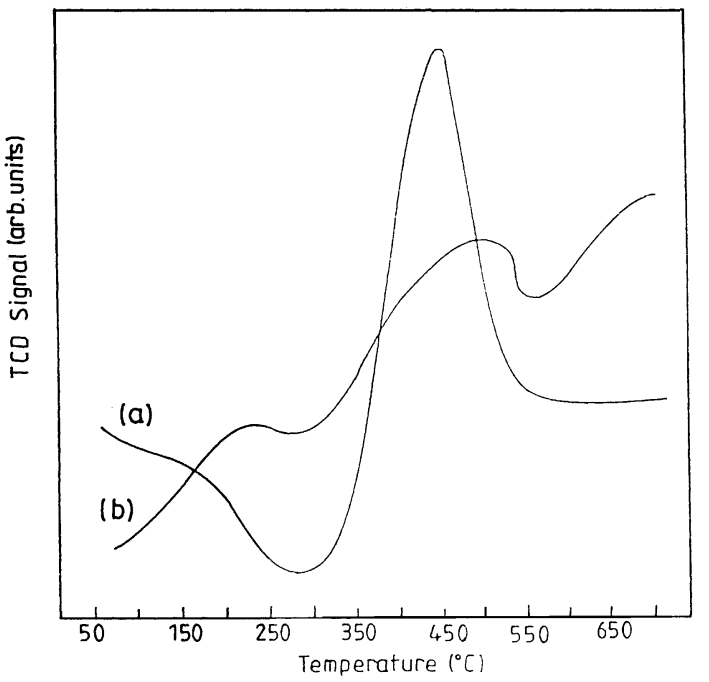

Fig. 9. TPR patterns of (a) mesoporous Cr-AlPO ; (b) Cr-MCM-48.

products observed on $\mathrm{Cr}-\mathrm{AlPO}_{4}$. On the surface of the mesoporous $\mathrm{Cr}-\mathrm{AlPO}_{4}$, both oxidation and dealkylation reactions take place simultaneously, leading to benzaldehyde and benzene as main products, whereas the redox nature of the Cr-MCM-48 governs the oxidation of toluene, giving aldehyde as the main product. The formation of benzene as a result of dealkylation reaction predominates on acid $\left(\mathrm{Al}^{3+}\right)$ sites, whereas, on redox sites $\left(\mathrm{Cr}^{5+/ 6+}\right)$ oxidation of toluene is taking place, leading to benzaldehyde.

The absence of the coupled products indicates that the reaction is taking place in a concerted manner where adsorption of toluene takes place parallel to the lattice. Oxygen atoms are adsorbed on the sites adjacent to the site holding the carbon atom of the methyl

Table 2

Catalytic activity of mesoporous $\mathrm{Cr}-\mathrm{AlPO}_{4}$ for the oxidation of toluene with molecular oxygen

\begin{tabular}{lllrr}
\hline Temperature $(\mathrm{K})$ & $\begin{array}{l}\text { Conversion of } \\
\text { toulene }(\%)\end{array}$ & \multicolumn{2}{l}{ Product selectivity $(\%)$} & \\
\cline { 3 - 5 } & & Benzaldehyde & Benzene & 6.4 \\
\hline 523 & 0.75 & 91.0 & 2.6 & 13.9 \\
548 & 0.90 & 83.5 & 3.0 & 36.6 \\
573 & 1.40 & 60.4 & 6.1 & 43.3 \\
598 & 2.23 & 50.6 & 8.2 & 49.4 \\
623 & 4.85 & 42.4 & 12.4 & 62.3 \\
648 & 9.19 & 25.3 & & $\mathrm{CO}_{2}+3$ \\
\hline
\end{tabular}


Table 3

Catalytic activity of Cr-MCM-48 for the oxidation of toluene with molecular oxygen

\begin{tabular}{llll}
\hline \multirow{2}{*}{$\begin{array}{l}\text { Temperature } \\
(\mathrm{K})\end{array}$} & $\begin{array}{l}\text { Conversion of } \\
\text { toulene }(\%)\end{array}$ & \multicolumn{2}{l}{ Product selectivity $(\%)$} \\
\cline { 3 - 4 } & & Benzaldehyde & $\left(\mathrm{CO}_{2}+\mathrm{CO}\right)$ \\
\hline 523 & 0.90 & 75.39 & 24.61 \\
548 & 1.24 & 61.57 & 38.43 \\
573 & 2.20 & 44.76 & 55.24 \\
598 & 3.40 & 33.90 & 66.10 \\
623 & 6.88 & 20.62 & 79.38 \\
648 & 11.33 & 16.0 & 84.0 \\
\hline
\end{tabular}

group. One of these sites donates its oxygen to the carbon atom of the methyl group, leading to the formation of carbon monoxide. Another oxygen atom reacts with hydrogen atoms of the methyl group, giving rise to water. Donation of hydrogen atoms from the acidic sites to the ring carbon completes the reaction with the formation of benzene.

At lower temperatures, redox properties of mesoporous $\mathrm{Cr}-\mathrm{AlPO}_{4}$ influence the reaction, leading to the formation of benzaldehyde in excess. As the temperature is increased, the selectivity to benzaldehyde drops down whereas the selectivity towards benzene increases, indicating the influence of acidity function. The conversion of toluene increased with increase of temperature. At higher temperatures, $\mathrm{CO}_{x}$ products may be mainly formed by consecutive oxidation of primary products.

In contrast, Cr-MCM-48 acts as a pure redox catalyst, giving rise to only benzaldehye as oxidation product. Further oxidation of benzaldehyde gives $\mathrm{CO}_{2}$ and $\mathrm{H}_{2} \mathrm{O}$. No significant amount of benzoic acid was detected on either catalyst. This confirms that the formation of aldehyde is a slow and rate-determining step and that further oxidation takes place at faster rate. The catalyst could be reused after calcination in air for $5 \mathrm{~h}$ at $673 \mathrm{~K}$. The loss of catalytic activity in the second run is $\sim 5 \%$.

\section{Conclusions}

Hexagonal mesoporous aluminophosphates-containing chromium could be successfully synthesized with better crystallinity. The system retains its morphology even after the removal of surfactant.
Mesoporous $\mathrm{Cr}-\mathrm{AlPO}_{4}$ exhibits both acidic and redox properties by promoting dealkylation and oxidation in a concerted manner, whereas, under the same experimental conditions, Cr-MCM-48 promotes only oxidation. On mesoporous $\mathrm{Cr}-\mathrm{AlPO}_{4}$ it is observed that, at lower temperatures, oxidation of toluene is favoured, whereas, at higher temperatures dealkylation reactions govern the final products formed.

\section{Acknowledgements}

The authors are thankful to Dr. Kiwi-Minsker, EPFL and Prof. D.V.S. Murthy, IIT Madras for fruitful discussions. We also thank M.R.K. Prasad and Suja for their help in characterising the catalysts.

\section{References}

[1] S.T. Wilson, B.M. Lok, C.A. Messina, T.R. Cannan, E.M. Flanigen, J. Am. Chem. Soc. 104 (1982) 1176.

[2] E.M. Flanigen, B.M. Lok, R.L. Patton, S.T. Wilson, in: Proceedings of the Seventh International Zeolite Conference, Tokyo, Japan, 1986, p. 103.

[3] J.C. Vartuli, K.D. Schmitt, C.T. Kresge, W.J. Roth, M.E. Leonowicz, S.B. McCullen, S.D. Hellring, J.S. Beck, J.L. Schlenker, D.H. Olson, E.W. Sheppard, Chem. Mater. 6 (1994) 2317.

[4] P.T. Tanev, T.J. Pinnavaia, Science 267 (1995) 865.

[5] K.M. Reddy, I. Moudrakovski, A. Sayari, J. Chem. Soc. Chem. Commun. (1994) 1059.

[6] N. Ulagappan, C.N.R. Rao, J. Chem. Soc. Chem. Commun. (1995) 875.

[7] R.K. Rana, B. Viswanathan, Catal. Lett. 52 (1998) 259.

[8] Ch. Subrahmanyam, B. Viswanathan, T.K. Varadarajan, Bull. Catal. Soc. India 10 (6) (2000) 1.

[9] S. Ayyappan, C.N.R. Rao, J. Chem. Soc. Chem. Commun. (1997) 575.

[10] Y. Feng, J. Xia, X. Feng, G.D. Stucky, J. Chem. Soc. Chem. Commun. (1997) 949.

[11] B. Chakraborty, A.C. Pulikottil, S. Das, B. Viswanathan, J. Chem. Soc. Chem. Commun. (1997) 911.

[12] M.P. Kapoor, A. Raj, Appl. Catal. A: Gen. 203 (2000) 311.

[13] T. Kimura, Y. Sugahara, K. Kuroda, J. Chem. Soc. Chem. Commun. (1998) 559.

[14] T. Kimura, Y. Sugahara, K. Kuroda, Chem. Mater. 11 (1999) 508.

[15] Ch. Subrahmanyam, B. Louis, F. Rainone, B. Viswanathan, A. Renken, T.K. Varadarajan, Catal. Commun. 3 (2002) 45.

[16] Ch. Subrahmanyam, B. Viswanathan, T.K. Varadarajan, Bull. Catal. Soc. India 1 (2002) 52. 
[17] Ch. Subrahmanyam, B. Louis, B. Viswanathan, A. Renken, T.K. Varadarajan, Eurasian Chem. Tech. J. 3 (2001) 59.

[18] D. Zhao, Z. Luan, L. Kevan, J. Chem. Soc. Chem. Commun. (1997) 1009.

[19] D. Zhao, Z. Luan, L. Kevan, J. Phys. Chem. 101 (1997) 6943.
[20] A.R. West, Basic Solid State Chemistry, Wiley, Chichester, 1988.

[21] E. Banks, E. Greenblatt, B.R. McGarvery, J. Chem. Phys. 47 (1967) 3772.

[22] B.M. Weckhuysen, R.A. Schoonheydt, Zeolites 14 (1994) 360. 